\title{
APLICAÇÃO DO BALANCED SCORECARD NO SETOR PÚBLICO: ESTUDO DE CASO EM UMA ASSESSORIA JURÍDICA DA ADMINISTRAÇÃO PÚBLICA
}

Resumo: O Balanced Scorecard constitui importante ferramenta para o planejamento estratégico. Embora tenha sido originalmente desenvolvido para a iniciativa privada, seu uso não é restrito a empresas, podendo ser utilizado na Administração Pública desde que seja adaptado às peculiaridades do caso. O objetivo deste estudo é fazer um exercício de aplicação da ferramenta Balanced Scorecard para uma Assessoria Jurídica da Administração Pública. Dos procedimentos metodológicos, trata-se de um estudo de caso realizado mediante observação participante para a coleta de dados. O estudo inicia com a aplicação da análise SWOT (forças, fraquezas, oportunidades e ameaças), somo suporte de diagnóstico organizacional para a aplicação do Balanced Scorecard. A aplicação desta ferramenta é adaptada com a priorização da perspectiva do cidadão, apresentando o desenvolvimento de metas para o setor e as iniciativas necessárias para alcance dos objetivos. $\mathrm{O}$ estudo contribui para a análise de um caso específico e com o encorajamento de aplicações futuras do Balanced Scorecard em instituições públicas, bem como unidades de informação (bibliotecas, arquivos e museus).

Palavras chave: Balanced Scorecard; Diagnóstico organizacional; Matriz SWOT; Estudo de Caso.

\author{
Ana Paula Cervi \\ Universidade Federal de Santa Catarina \\ Graduanda em Ciência da Informação \\ anacervi@gmail.com \\ Ana Clara Candido \\ Doutora em Avaliação de Tecnologia \\ Universidade Nova de Lisboa \\ Universidade Federal de Santa Catarina . \\ Professora Departamento de Ciência da \\ Informação e Programa de Pós Graduação \\ em Ciência da Informação-UFSC \\ acc.anaclara@gmail.com
}

\section{BALANCED SCORECARD APPLICATION IN THE PUBLIC SECTOR: CASE STUDY IN A PUBLIC ADMINISTRATION LEGAL ADVISORY}

\begin{abstract}
Balanced Scorecard is an important tool for strategic planning. Although it was originally developed for the private sector, its use is not restricted to companies and can be used in the Public Administration provided it is adapted to the peculiarities of the case. The aim of this study is to do an exercise of application of the tool Balanced Scorecard for a Legal Advice of the Public Administration. From the methodological procedures, this is a case study carried out through participant observation to collect data. The study begins with the application of SWOT analysis (strengths, weaknesses, opportunities and threats), and support of organizational diagnosis for the application of the Balanced Scorecard. The application of this tool is adapted with the prioritization of the citizen's perspective, presenting the development of goals for the sector and the initiatives necessary to achieve the objectives. The study contributes to the analysis of a specific case and the encouragement of future applications of the Balanced Scorecard in public institutions, as well as information units (libraries, archives and museums).
\end{abstract}

Keywords: Balanced Scorecard; Organizational Diagnosis; SWOT Analysis; Case Study. 


\section{INTRODUÇÃO}

A Unidade de Informação na qual o presente estudo se baseia é uma assessoria jurídica de um órgão de administração pública. Embora sua atividade principal seja a elaboração de recursos judiciais, esta unidade presta informações acerca dos processos judiciais nos quais atua, especialmente aos usuários internos, atendendo a solicitações de outros órgãos da instituição.

As informações vão desde relatórios estatísticos relativos aos recursos interpostos até teses recursais das controvérsias jurídicas, atuando com maior incidência em casos de improbidade administrativa.

Tendo em vista que todos os servidores lotados na coordenadoria em questão possuem formação jurídica, o setor carece de conhecimento técnico para otimização das atividades internas, razão pela qual se mostra necessário o desenvolvimento de um planejamento estratégico para melhor atender aos objetivos da instituição.

A fim de determinar as variáveis que envolvem a qualidade nos serviços prestados pela Assessoria Jurídica, utilizou-se o método SWOT (sigla em inglês Strengths, Weaknesses, Opportunities e Threats) para identificar os fatores internos e externos envolvidos, listando forças, fraquezas, ameaças e oportunidades.

Após a aplicação da matriz SWOT, optou-se pela aplicação do Balanced Scorecard (BSC), a fim de elaborar um mapa estratégico da organização. Tratando-se de um órgão público, foi necessário buscar por um modelo de BSC adaptado às características do contexto em causa, que prioriza o atendimento ao cidadão como prioridade máxima, deslocando a perspectiva financeira para segundo plano

\section{DIAGNÓSTICO ORGANIZACIONAL}

As atividades do setor de assessoria jurídica deste estudo vão além da interposição de recursos perante os Tribunais Superiores. Embora essa seja sua principal função, existe dispositivo legal que prevê a função de manter um sistema de acompanhamento e controle das decisões judiciais e dos prazos recursais, especialmente naqueles que versem sobre matéria objeto de teses defendidas pela instituição. 
O sistema de acompanhamento e controle de decisões e prazos é necessário para monitoramento das atividades internas do setor, elaboração de relatórios estatísticos em geral, redação do boletim informativo trimestral e prestação de informações solicitadas por outros setores da instituição.

Para auxiliar nas atividades citadas, são utilizadas diversas planilhas eletrônicas, bem como o sistema Qlikview, que consiste em uma ferramenta de software para visualização de dados que possibilita criar aplicativos e painéis de análise guiada altamente interativos.

Araújo Jr. (2005) afirma que, dentre os elementos mais importantes para a concepção e implementação do planejamento estratégico, está a elaboração do diagnóstico estratégico que visa reunir informações-chave para o desenvolvimento das diretrizes e das estratégias a serem utilizadas no âmbito do planejamento, mediante a análise dos meios ambientes interno e externo da unidade.

De acordo com Paludo (2013), a finalidade do diagnóstico organizacional "é identificar os pontos fortes e fracos da organização, e analisar as oportunidades e ameaças com as quais a organização vai ter que lidar no ambiente externo".

A análise interna é o meio que permite uma avaliação dos pontos fortes e pontos fracos que a organização possui. Os pontos fortes constituem as forças propulsoras da organização que facilitam o alcance dos objetivos organizacionais, enquanto que os pontos fracos constituem as limitações e restrições que dificultam ou impedem seu alcance (CHIAVENATO, 2003).

Pontos fortes são competências, fatores ou características positivas que a organização possui e que favorecem o cumprimento de sua missão, devendo ser considerados na elaboração das estratégias. Pessoal qualificado também é considerado um ponto forte da organização.

Pontos fracos são as deficiências, fatores ou características negativas que se encontram presentes na organização e prejudicam o cumprimento de sua missão, devendo ser objeto de programas específicos para eliminá-los ou minimizá-los. (PALUDO, 2013, p. 237)

Já a análise do ambiente externo deve mapear as condições externas da organização no sentido de fazer um conjunto de previsões sobre o futuro dessas condições, que envolvem a conjuntura econômica, tendências políticas, sociais, culturais e legais que afetam a sociedade e a instituição (CHIAVENATO, 2003).

Para organização dos dados e informações coletados no presente estudo, foi utilizada a ferramenta $S W O T$, que consiste na essência de qualquer planejamento estratégico, dada a " $a$ 
importância do monitoramento ambiental ao extrair dos ambientes organizacionais, informações básicas para o planejamento” (ARAÚJO JR., 2005).

Quadro 01: Fatores internos (Força e Fraqueza) e externos (Oportunidades e Ameaças) esquematizados da organização.

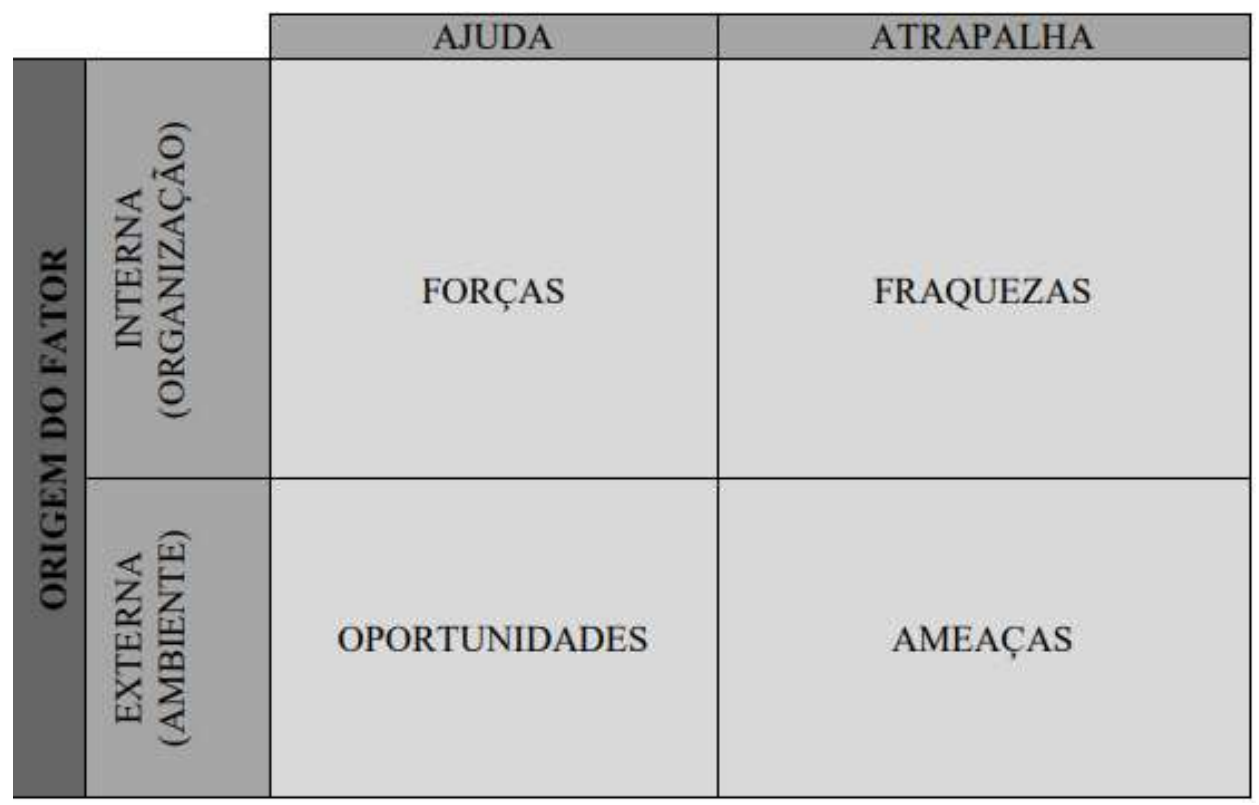

Fonte: Value Based Management (2011) apud FEIL; HEINRICHS (2012)

Ao contrário de organizações privadas que visam o lucro, a administração pública tem a finalidade de prestar serviços públicos na busca do bem-estar social, de modo que este papel social deve ser exercido com a maior qualidade, eficiência e eficácia possível na sua prestação de serviço à população. Assim como as demais organizações, as públicas também exibem forças e fraquezas bem como oportunidades e ameaças que devem ser levadas em consideração. Como pontos fortes dentro da Assessoria Jurídica, podemos mencionar:

a) Instalações físicas adequadas: A Assessoria Jurídica dispõe de 7 (sete) salas amplas, climatizadas, com iluminação natural e espaços individuais para cada colaborador, estando distribuídas entre uma sala para o Coordenador, uma para cada Assessor, uma sala para o Apoio Administrativo, uma para a Assessoria Jurídica, uma para os estagiários e uma pequena sala para reuniões. 
b) Equipamentos modernos: Cada colaborador tem a sua disposição um computador modelo All-in-one HP Compaq Elite 8300, que possui configuração adequada para as atividades desempenhadas dentro da coordenadoria, bem como acesso à internet em tempo integral.

c) Boletim informativo: o boletim informativo trimestral apresenta notícias em destaque referentes a decisões judiciais que resultaram em êxito por parte da instituição, bem como dados quantitativos das atividades desempenhadas e dados estatísticos quanto aos resultados obtidos. É uma ferramenta que resume o trabalho realizado no trimestre pela coordenadoria de forma visual, que é disponibilizada para todos os membros, servidores e comissionados da instituição, os quais apresentam feedback positivo em face às informações prestadas.

d) Competência jurídica dos membros: Tanto o Coordenador, quanto os Assessores, são membros da instituição com vasto conhecimento jurídico e anos de experiência na área, estando plenamente capacitados a orientar e decidir acerca das demandas judiciais, bem como quanto aos procedimentos internos do setor.

e) Credibilidade com a instituição: A Assessoria Jurídica possui alta credibilidade junto ao demais órgãos da instituição, prestando informações acerca das atividades desenvolvidas, tirando dúvidas e auxiliando dentro das possibilidades.

Por outro lado, os principais pontos fracos são:

a) Excesso de rotinas repetitivas: Tendo em vista a formação exclusivamente jurídica dos membros da equipe, a coordenadoria desenvolve suas atividades administrativas de forma precária e repetitiva, muitas vezes incorrendo em retrabalhos, o que impacta negativamente na qualidade do serviço prestado.

b) Alta rotatividade da equipe: Dos 18 cargos dentro da coordenadoria, apenas 4 são referentes a servidores efetivos lotados no setor, havendo grande rotatividade entre estagiários e comissionados, o que faz com que muito tempo seja perdido treinando colaboradores novos que não permanecem no setor a longo prazo. 
c) Pessoas desmotivadas: A complexidade das atividades e o excesso de cobrança por resultados acaba por intimidar e desmotivar os colaboradores, que muitas vezes não se sentem capacitados para o serviço, o que também impacta na alta rotatividade da equipe.

d) Servidores desatualizados: Servidores com muito tempo de serviço tendem a demonstrar resistência às mudanças, especialmente as tecnológicas, sobrecarregando outros colaboradores da equipe com atividades que não sabem realizar.

e) Sistema Qlikview: A coordenadoria dispõe da ferramenta Qlikview, uma plataforma de business discovery que permite analisar os dados de todas as fontes, em tempo real, para promover a visualização dos dados relativos às atividades desempenhadas. No entanto, a maior parte dos demais setores não possui treinamento para utilização da ferramenta, de modo que o trabalho realizado pela coordenadoria acaba tendo pouca visibilidade.

Partindo para o âmbito externo, temos como oportunidades:

a) Criação de novos cargos: $A$ administração superior da instituição está constantemente monitorando a necessidade de expansão do quadro funcional, de modo que é possível a ampliação da equipe mediante Projeto de Lei Complementar que preveja a criação de novos cargos para a instituição.

b) Cursos de capacitação: O Centro de Estudos e Aperfeiçoamento Funcional (CEAF) tem como finalidade promover o aperfeiçoamento profissional e cultural de membros e servidores da instituição, organizando a realização de cursos e seminários, entre outros, nos quais a equipe da coordenadoria pode se inscrever, visando o crescimento e aprimoramento na execução das atividades.

Por fim, listam-se como ameaças: 
a) Exoneração ou relocação de servidores capacitados: É comum que servidores jovens permaneçam em busca de cargos melhores, mediante a realização de outros concursos públicos ou pedidos de relocação dentro da instituição. Tratando-se de um cargo público, não é possível fazer uma contraproposta financeira para que permaneça, nem exigir aviso prévio diante da saída de um servidor.

b) Restrições orçamentárias: Sendo uma instituição pública, está sujeita a restrições orçamentárias, devendo respeitar os limites previstos na Lei de Responsabilidade Fiscal (LRF). Os referidos limites podem implicar no não preenchimento de cargos vagos na equipe da coordenadoria em razão da necessidade de contenção de despesas, conforme os limites de gastos com pessoal previstos nos artigos 22 e 23 da LRF:

Art. 22. A verificação do cumprimento dos limites estabelecidos nos arts. 19 e 20 será realizada ao final de cada quadrimestre.

Parágrafo único. Se a despesa total com pessoal exceder a 95\% (noventa e cinco por cento) do limite, são vedados ao Poder ou órgão referido no art. 20 que houver incorrido no excesso:

[...]

IV - provimento de cargo público, admissão ou contratação de pessoal a qualquer título, ressalvada a reposição decorrente de aposentadoria ou falecimento de servidores das áreas de educação, saúde e segurança;

[...]

Art. 23. Se a despesa total com pessoal, do Poder ou órgão referido no art. 20, ultrapassar os limites definidos no mesmo artigo, sem prejuízo das medidas previstas no art. 22, o percentual excedente terá de ser eliminado nos dois quadrimestres seguintes, sendo pelo menos um terço no primeiro, adotando-se, entre outras, as providências previstas nos $\S \S 3^{\circ}$ e $4^{\circ}$ do art. 169 da Constituição.

$\S 1^{\circ}$ No caso do inciso I do $\S 3^{\circ}$ do art. 169 da Constituição, o objetivo poderá ser alcançado tanto pela extinção de cargos e funções quanto pela redução dos valores a eles atribuídos. (Grifo nosso)

Tendo em vista os pontos fortes e fracos, e oportunidades e ameaças mencionados, foi possível obter como resultado a matriz SWOT abaixo: 


\section{Quadro 1 - Matriz SWOT}

\begin{tabular}{|c|c|c|}
\hline \multirow{4}{*}{$\begin{array}{c}\text { Fatores } \\
\text { internos }\end{array}$} & Forças & Fraquezas \\
\cline { 2 - 3 } & Instalações físicas adequadas & Excesso de rotinas repetitivas \\
\cline { 2 - 3 } & Equipamentos modernos & Alta rotatividade da equipe \\
\cline { 2 - 3 } & Boletim informativo & Pessoas desmotivadas \\
\cline { 2 - 3 } & Competência jurídica dos membros & Servidores desatualizados \\
\cline { 2 - 3 } Fatores & Credibilidade com a instituição & Sistema Qlikview \\
\hline \multirow{3}{*}{ externos } & Oportunidades & Ameaças \\
\cline { 2 - 3 } & $\begin{array}{c}\text { Criaçāo de novos cargos, ampliando } \\
\text { o quadro funcional }\end{array}$ & $\begin{array}{c}\text { Exoneração ou relotação de } \\
\text { servidores capacitados }\end{array}$ \\
\cline { 2 - 3 } & Cursos de capacitaçāo & Restrições orçamentárias \\
\hline
\end{tabular}

Fonte: Elaboração Própria (2018).

\section{PROCEDIMENTOS METODOLÓGICOS}

No que tange aos procedimentos técnicos utilizados, classifica-se a pesquisa como estudo de caso, o qual consiste no estudo aprofundado de um ou poucos objetos, de maneira que permita seu amplo e detalhado conhecimento, tarefa praticamente impossível mediante outros delineamentos já considerados, podendo ser utilizado para "descrever a situação do contexto em que está sendo feita determinada investigação" (GIL, 2002, p. 54). Ainda de acordo com o autor, nos estudos de caso os dados podem ser obtidos mediante análise de documentos, entrevistas, depoimentos pessoais, observação espontânea, observação participante e análise de artefatos físicos.

O presente estudo de caso adotou a observação participante como método de coleta de dados, mediante o ponto de vista da autora, com base no período trabalhado junto à uma Assessoria Jurídica da Administração Pública ${ }^{1}$, de 10/03/2013 até 11/05/2018. A observação participante, de acordo com Becker e Geer (1969) apud ABIB et al. (2013, p. 660), é:

[...] um método no qual o observador participa do dia a dia das pessoas que estão sendo estudadas, seja abertamente no papel de pesquisador ou secretamente em algum papel disfarçado, observando como as coisas acontecem, ouvindo o que é dito e questionado pelas pessoas durante um período de tempo.

1 A informação sobre o local da aplicação não será revelada neste estudo, sendo a instituição estudada designada de Assessoria Júridica de um órgão de Administração Pública. 
Sendo assim, de acordo com Angrosino (2009) apud ABIB et al. (2013), os resultados são obtidos de modo indutivo e dialógico, ou seja, as conclusões podem ser discutidas com os informantes à medida que a observação se desenrola e as interpretações vão sendo construídas pelo pesquisador.

O autor caracteriza a observação participante como um processo de aprendizagem pelo envolvimento nas atividades cotidianas de quem participa da pesquisa, não devendo ser considerada apenas um método de pesquisa, porque ela é, antes de tudo, "uma estratégia que facilita a coleta de dados no campo" que combina o papel do pesquisador (participante de algum modo) com técnicas de coleta de dados (observação).

\section{APLICAÇÃO DO BALANCED SCORECARD (BSC)}

Vinculando as estratégias originárias da matriz SWOT às perspectivas do Balanced Scorecard é possível a construção de um mapa estratégico relacionado aos fatores de sucesso, internos e externos, que afetam a organização, o que, consequentemente, auxiliará na elaboração do planejamento estratégico (LEE; KO, 2000 apud FERNANDES, 2013).

Nas palavras de Silva (2009, p. 10), o BSC:

[...] foi originalmente criado para aplicação em organizações que têm como objetivo a obtenção de lucro. Sendo um modelo idealizado para o sector privado teve de sofrer ajustamentos para poder ser utilizado no sector público, desde logo justificados pelo fato de estas organizações não visarem à obtenção de lucro. As características destas organizações são muito particulares destacando-se desde logo a excessiva burocracia existente e a hierarquia rígida $[\ldots]$.

Esta visão da gestão do desempenho associada a um plano de ação integrado ao BSC pode ser aplicada a qualquer organização, seja privada ou pública. No entanto, é preciso adotar outros conceitos nas organizações públicas, sendo necessário fazer algumas adaptações e gerenciar ações específicas que diferenciam a condução da gestão (MENDES et al., 2012 apud FERNANDES, 2013). 


\subsection{O BALANCED SCORECARD NO SETOR PÚBLICO}

O Balanced Scorecard na esfera pública deve considerar ações direcionadas para garantir efetividade, eficácia e eficiência, eis que qualquer organização pública, para prestar serviços com excelência, precisa realizar a sua função social com qualidade na prestação de serviços e com o menor consumo de recursos possível (GHELMAN; COSTA, 2006).

Kaplan e Norton (1997), como criadores da ferramenta, afirmam que o Balanced Scorecard na Administração Pública potencializa a razão principal da sua existência, consistente em servir à população e não apenas controlar os gastos orçamentais.

Considerando que o êxito financeiro não é o principal objetivo das organizações públicas, estas não podem utilizar a arquitetura padrão das perspectivas e do mapa estratégico do BSC original, segundo os quais os objetivos financeiros são os principais resultados a serem alcançados (KAPLAN; NORTON, 2010; MATIAS-PEREIRA, 2012).

\subsection{AS PERSPECTIVAS DO BSC NA ADMINISTRAÇÃO PÚBLICA}

Fernandes (2013) afirma que, enquanto o setor privado visa o lucro, a esfera pública presta serviços à coletividade. O Balanced Scorecard aplicado em organizações públicas deve adaptar suas perspectivas, para que se ajustem melhor à sua realidade, sempre mantendo uma relação lógica de causalidade, em que, ao final, deverão estar o cidadão e a sociedade a quem procuram servir, os quais se configuram como a razão de ser destas organizações.

O modelo original do Balanced Scorecard foi estruturado com quatro perspectivas ou focos, tendo como objeto as organizações com fins lucrativos. As perspectivas originais são: Financeira, Clientes, Processos Internos, Aprendizado e Crescimento. Não se localiza na descrição da proposta alguma restrição à mudança de prioridade das perspectivas. Isto é muito importante para a flexibilização do modelo, porque dependendo dos objetivos da instituição, em particular, as prioridades de resultado podem ser de natureza não-financeira. (SANTOS, 2013, p. 6)

No caso específico de instituições públicas (administrações municipais) poderia ser iniciado o trabalho com quatro perspectivas, priorizando-se o foco ou perspectiva do cidadão, conforme a figura abaixo: 
Figura 1: Modelo de BSC para o setor público

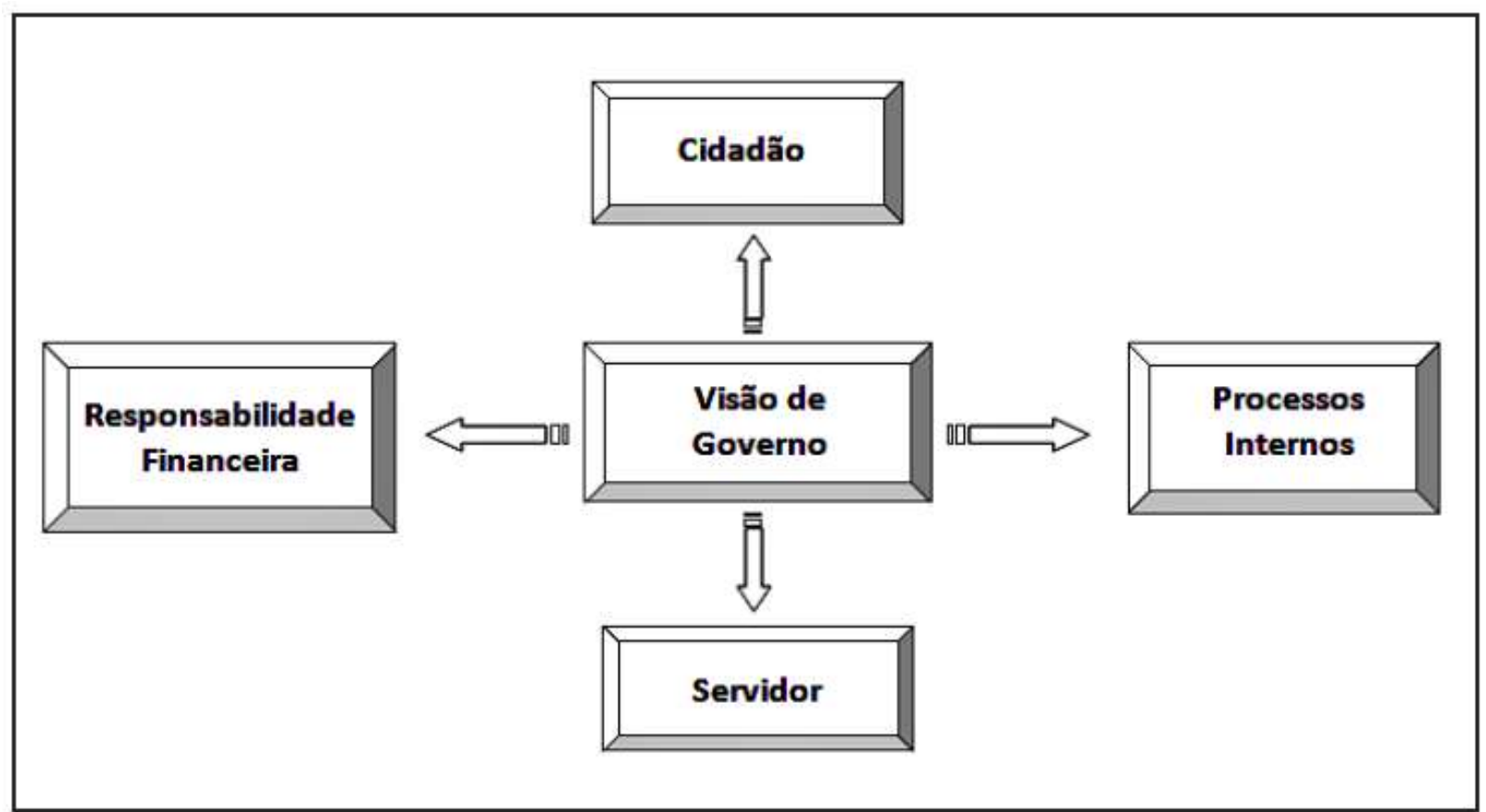

Fonte: Santos (2003, p. 86).

Segundo o modelo de Santos (2003), a perspectiva do cidadão encontra-se no topo da cadeia, substituindo a perspectiva do cliente, dizendo respeito a como a organização deve proceder para atender às necessidades dos cidadãos.

Já perspectiva financeira foi deslocada para a segunda posição e adaptada para uma perspectiva da responsabilidade financeira, de como a organização deve proceder para financiar os projetos e atender à Lei de Responsabilidade Fiscal.

A perspectiva dos processos internos leva em conta como estão sendo gerenciados e inovados os processos internos na organização, no intuito de atender às expectativas do cidadão e da Lei de Responsabilidade Fiscal.

Por fim, a perspectiva do servidor entra no lugar da perspectiva da aprendizagem, analisando como estão sendo sustentadas a habilidade e a criatividade dos servidores para atender às expectativas dos cidadãos. 


\subsubsection{Perspectiva do cidadão}

No Brasil impera o princípio da impessoalidade, que veda o tratamento diferenciado entre os cidadãos, razão pela qual Ghelman e Costa (2006) consideram que essa perspectiva deve ser retratada de maneira completamente diferente da esfera privada.

Kaplan e Norton (2010) apud FERNANDES (2013) defendem que os cidadãos e beneficiários dos serviços prestados pelas instituições da esfera pública devem ser colocados no topo do mapa estratégico, como no modelo de Santos, pois o sucesso destas organizações é diretamente associado ao alcance da eficácia na prestação de benefícios para a população.

\subsubsection{Perspectiva da responsabilidade financeira}

$\mathrm{Na}$ Administração Pública, o aspecto financeiro se refere ao orçamento, que configura como um fator limitador das ações de governo. Sem uma boa execução orçamentária, dificilmente uma instituição pública conseguirá obter recursos para a aquisição de equipamentos, para a manutenção da sua infraestrutura e para a qualificação de seus funcionários.

Consequentemente, um bom desempenho dos objetivos financeiros impacta positivamente as outras perspectivas (GHELMAN, 2006).

\subsubsection{Perspectiva dos processos internos}

De acordo com Ghelman (2006), é por meio da racionalização dos recursos públicos que o Estado busca atender satisfatoriamente à população, sendo necessário melhorar a qualidade do gasto público, reduzindo custos, evitando o desperdício e aumentando a produtividade na prestação de serviços públicos, de modo que a perspectiva dos processos internos com foco na eficiência contribui para este objetivo.

Kaplan e Norton (2000) complementam que a perspectiva dos processos internos no âmbito da Administração Pública deve voltar-se para a melhoria dos processos e a consequente eficiência nas ações públicas, que possibilitarão satisfazer, da melhor forma, as necessidades do cidadão. 


\subsubsection{Perspectiva dos servidores}

No intuito de combater o nepotismo, é vedada a contratação de funcionários sem concurso público. Dessa forma, mesmo que uma autarquia, fundação ou órgão da Administração Pública necessite de um profissional com um determinado perfil, ele só poderá ser contratado mediante aprovação em concurso público (GHELMAN; COSTA, 2006).

Não obstante, é comum que a remuneração de servidores públicos altamente especializados e capacitados esteja defasada em relação ao mercado, o que torna difícil a retenção desses servidores, mesmo com a estabilidade proporcionada pela Administração Pública.

Além disso, de acordo com Ghelman e Costa (2006), a política de remuneração do serviço público não diferencia o servidor que exerce com excelência as suas funções do servidor que desempenha de forma ineficiente o seu papel e não alcança o resultado esperado.

Para tentar contornar as limitações na gestão de recursos humanos na esfera pública, deve existir um esforço em treinamento, no intuito de aumentar a qualificação dos funcionários, os quais passarão a ter maior capacidade de promover mudanças significativas em tecnologia, métodos e processos que acarretarão uma melhora dos produtos e serviços ofertados pela organização. (FERNANDES, 2013, pp.74-75)

\subsection{Mapa estratégico}

Conforme já mencionado, enquanto no setor privado as ações previstas no planejamento estratégico têm como objetivo primordial a maximização do lucro, a estratégia a ser seguida pela organização pública tem como objetivo cumprir a sua função social, atendendo ao cidadão.

Kaplan e Norton (2010) apud FERNANDES (2013) afirmam que, em função dessa mudança de foco, a relação de causalidade entre as perspectivas do BSC apresenta uma dinâmica diferente no âmbito das organizações públicas.

O mapa estratégico serve para demonstrar o alinhamento dos indicadores com os propósitos e objetivos estratégicos e permite a visualização da contribuição das diversas funções da instituição e o relacionamento das iniciativas (SANTOS, 2013).

Como resultado da aplicação do BSC derivado da análise SWOT das atividades desenvolvidas na Assessoria Jurídica, tem-se o mapa estratégico abaixo, seccionado conforme cada uma das perspectivas do modelo proposto por Santos (2003): 
Quadro 2 - Perspectiva do Cidadão

\begin{tabular}{|l|c|c|}
\hline \multirow{4}{*}{ Cidadăo } & Objetivos & Excelência no atendimento \\
\cline { 2 - 3 } & Indicadores & Feedback dos cidadẫos mediante pesquis de opiniẵo \\
\cline { 2 - 3 } & Metas & Manter a aprovaçấo popular acima de 75\% \\
\cline { 2 - 3 } & Iniciativas & Programa de gestẫo da qualidade \\
\hline
\end{tabular}

Fonte: Elaboração Própria (2018).

Quadro 3 - Perspectiva da Responsabilidade Financeira

\begin{tabular}{|c|c|c|}
\hline \multirow{4}{*}{$\begin{array}{l}\text { Responsabilidade } \\
\text { financeira }\end{array}$} & Objetivos & $\begin{array}{l}\text { Obedecer a Lei de Responsabilidade Fiscal (LRF); Otimizar a gestão de } \\
\text { recursos }\end{array}$ \\
\hline & Indicadores & Percentual do orçamento utilizado; Portal da Transparência \\
\hline & Metas & $\begin{array}{l}\text { Manter a despesa total com pessoal abaixo de } 95 \% \text { do limite definido na } \\
\text { LRF }\end{array}$ \\
\hline & Iniciativas & Reuniốes mensais para monitoramento dos gastos \\
\hline
\end{tabular}

Fonte: Elaboração Própria (2018).

Quadro 4 - Perspectiva dos Processos Internos

\begin{tabular}{|c|c|c|}
\hline \multirow{4}{*}{ Processos intemos } & Objetivos & Otimizar as rotinas de trabalho; Elevar a produtividade \\
\cline { 2 - 3 } & Indicadores & Percentual de êxito nas decisóes judiciais \\
\cline { 2 - 3 } & Metas & Atingir uma média mensal de 70\% das decisóes favoráveis \\
\cline { 2 - 3 } & Iniciativas & $\begin{array}{c}\text { Revisăo dos procedimentos; Realizaçấo de reuniớes para } \\
\text { compartilhamento dos resultados positivos }\end{array}$ \\
\hline
\end{tabular}

Fonte: Elaboração Própria (2018).

Quadro 5: Perspectiva dos Servidores

\begin{tabular}{|c|c|c|}
\hline \multirow{4}{*}{ Servidores } & Objetivos & $\begin{array}{l}\text { Elevar a motivaçãa dos servidores; Fortalecer a integraçấo de membros e } \\
\text { servidores; Promover um ambiente de trabalho agradável e profissional; } \\
\text { Ampliar o quadro funcional }\end{array}$ \\
\hline & Indicadores & $\begin{array}{c}\text { Percentual de servidores atendidos; Pesquisas anônimas de opiniăo dos } \\
\text { servidores }\end{array}$ \\
\hline & Metas & Manter uma taxa de retençăo de talentos acima de $80 \%$ ao ano \\
\hline & Iniciativas & $\begin{array}{c}\text { Programa de treinamento e capacitação; Programa de gestấo por } \\
\text { competências; Elaboraçấo de Projeto de Lei Complementar para criaçăo } \\
\text { de novos cargos }\end{array}$ \\
\hline
\end{tabular}

Fonte: Elaboração Própria (2018).

\section{CONSIDERAÇÕES FINAIS}

A partir do referencial teórico, o presente estudo de caso apresentou a relevância da matriz SWOT para identificação dos pontos fortes e fracos, bem como oportunidades e ameaças, levando em conta os ambientes interno e externo. 
Ficou demonstrado que, embora disponha de recursos adequados para realização do trabalho, a Assessoria Jurídica apresenta problemas quanto à satisfação pessoal da equipe, decorrente das elevadas cobranças por resultado. Notou-se também a necessidade de uma revisão nos procedimentos internos para otimização das rotinas e a promoção de cursos de capacitação para os servidores.

O desenvolvimento do trabalho demonstrou que o diagnóstico organizacional também pode ser utilizado por instituições públicas, e não apenas empresas privadas, que busquem excelência nos serviços prestados.

Dadas as peculiaridades da gestão pública, foi realizada uma pesquisa em busca de um modelo de Balanced Scorecard adaptado, sendo escolhido o modelo de Santos, no qual a perspectiva da aprendizagem e crescimento passou a ser a perspectiva do servidor público, mantendo a perspectiva dos processos internos e priorizando o cliente, que passa a ser o cidadão, em relação à responsabilidade financeira do ente público.

O BSC permitiu o mapeamento de objetivos para a Assessoria Jurídica e a definição de indicadores para aferimento dos resultados. Foi possível, ainda, o estabelecimento de metas a serem atingidas e as iniciativas que deverão ser implantadas para que tais medidas se concretizem.

Diante do estudo de caso, pode se perceber a importância do BSC e sua aplicabilidade a diferentes tipos de organizações como ferramenta de apoio, sejam públicas ou privadas, ante a visão global da organização sob diferentes indicadores de resultado proporcionada pela ferramenta. 


\section{REFERÊNCIAS}

ABIB, Gustavo; HOPPEN, Norberto; HAYASHI JUNIOR, Paulo. Observação participante em estudos de administração da informação no Brasil. Revista de Administração de Empresas, [s.1.], v. 53, n. 6, p.604-616, dez. 2013. Disponível em: $<$ http://www.scielo.br/scielo.php?script=sci_arttext\&pid=S0034$75902013000600008 \& \operatorname{lng}=$ pt\&tlng=pt $>$ Acesso em: 3 jun. 2018.

ARAÚJO JR. Rogério Henrique de. Uso da técnica SWOT em unidades arquivísticas: subsídios para o planejamento estratégico. In: $6^{\circ}$ Congresso de Arquivologia do Mercosul, Campos do Jordão, 17 a 20 de outubro de 2005. Anais. Disponível em: $<$ http://repositorio.unb.br/bitstream/10482/1003/1/EVENTO_PlanejamentoUnidadeArquivisti ca.pdf $>$ Acesso em: 10 jun. 2018.

BRASIL. Lei Complementar n. 101, de 4 de maio de 2000. Estabelece normas de finanças públicas voltadas para a responsabilidade na gestão fiscal e dá outras providências. Disponível em: $<$ http://www.planalto.gov.br/ccivil_03/Leis/lcp/Lcp101.htm>. Acesso em: 2 jun. 2018.

CHIAVENATO, Idalberto. Introdução à Teoria Geral da Administração. 7. ed. rev. e atual. Rio de Janeiro: Elsevier, 2003.

FEIL, André A. HEINRICHS, Alexandre. Aplicação da Análise da Matriz SWOT em 5 Agências de Atendimento de uma Cooperativa de Crédito Situada no Vale do Taquari RS. Revista Eletrônica de Administração (Online), v. 11, n.1, ed. 20, jan-jun 2012. Disponível em: <http://periodicos.unifacef.com.br/index.php/rea/article/download/498/472>. Acesso em: 10 jun. 2018.

FERNANDES, Alan Gabriel. Balanced scorecard aplicado à Administração Pública: uma proposta de planejamento estratégico para o departamento de administração e economia da Universidade Federal de Lavras. Dissertação (Dissertação em administração pública) UFLA. Lavras, 2013.

GHELMAN, S.; COSTA, S. R. R. Adaptando o BSC para o setor público utilizando os conceitos de efetividade, eficácia e eficiência. In: SIMPÓSIO DE EXCELÊNCIA EM GESTÃO E TECNOLOGIA, 3., 2006, Resende. Anais... Resende, 2006. Disponível em: $<$ http://www.simpep.feb.unesp.br/anais/anais_13/artigos/137.pdf $>$. Acesso em: 10 jun. 2018.

GIL, Antônio Carlos. Como elaborar projetos de pesquisa. 4. ed. São Paulo: Atlas, 2002.

PALUDO, Augustinho. Administração pública. 3. ed. Rio de Janeiro: Elsevier, 2013.

SANTOS, Nivaldo João. Planejamento e orçamento na área pública: uma aplicação do Balanced Scorecard. In: ENCONTRO NACIONAL DE ENGENHARIA DE PRODUÇÃO, 23., 2003, Anais. Ouro Preto: ABEPRO, 2003. Disponível em: <www.abepro.org.br/biblioteca/ENEGEP2003_TR0702_0088.pdf > Acesso em: 6 jun. 2018.

SILVA, R. F. P. B. O Balanced Scorecard Aplicado à Administração Pública: um Modelo Aplicável a uma Instituição de Ensino Superior. Portugal: Universidade do Porto, 2009. 
Disponível em: Disponível em: $\quad<$ https://repositorioaberto.up.pt/bitstream/10216/20596/2/TESEFINAL.pdf>. Acesso em: 6 jun. 2018. 